\title{
Portfolio Structuring Model for Urban Infrastructure Investments
}

\author{
Francesca Medda, Francesco Caravelli, Athena Panayotou and Eleni Rapti \\ QASER Laboratory, University College London, UK
}

\begin{abstract}
The objective of this work is to propose a new methodology based on the concept of portfolio structuring for urban infrastructure investment. We argue that city investments need to be treated as an integrated and interdependent entity and from this perspective, the portfolio methodology is proposed in order to assess the non-financial impacts of infrastructure projects and then combine them in a portfolio of investments from a financial perspective. The methodology is applied for a set of project under the EIB JESSICA Initiative. The methodology shows that not only is it possible to develop a practical decision support system to assist stakeholders in assessing the performance of individual urban infrastructure projects, but also how it is possible to combine projects into a portfolio. The method exceeds the simple analysis of returns of individual investment schemes and capitalizes on effective and integrated management of projects/investment. And this is the key to devising a focused response which will enable therefore cities to be globally competitive, via innovative financial and business models.
\end{abstract}

Keywords: City, Integrated Finance, Portfolio, Investment

\section{SUBHEAD REQUIRED}

The present global tightening of credit has restricted local governments and private firms in their capacity to leverage debt in order to finance investments in urban development, especially when they advocate far-reaching sustainable solutions. High cost considerations and protracted delivery timetables continue to deter decision-makers and private investors from adopting innovative financing solutions as an alternative for investing in urban projects. However, we need to keep in mind that despite the bankruptcy of Detroit, city authorities continue to give the private sector carte blanche in some cases to invest in such piecemeal projects as, for example, multiplex cinemas, Wifi upgrades in high rise apartments and waterfront features. Nevertheless, a new urban paradigm which embeds economic, environmental and social aspects within innovative financial mechanisms is now emerging. Central to this new paradigm are creativity, knowledge and access to information as the fundamental drivers of the new urban finance.

Creativity in our context refers to the formulation of innovative financial mechanisms such as crowdsourcing, peerto-peer lending and impact investments, to mention a few. These financial advances are particularly evident at the micro-urban level, i.e. as bottom-up manifestations where the average citizen can participate in new urban initiatives. Citizens are nowadays less passive consumers and are instead increasingly finding and building their own solutions to overcome obstacles. For instance, e-Adept is an initiative in the city of Stockholm that enables visually-impaired people to navigate the city using open data. With an investment of $£ 500.000$, the city now generates economic benefits of £20.000.000.

Urban investments should therefore be treated as an integrated and interdependent entity, and from this perspective we propose the concept of portfolio investment where, rather than piecemeal projects, cities invest in differentiated 
yet integrated investments. This type of approach would constitute a viable solution for the urban investments, particular infrastructure investments.

A portfolio of diverse urban projects is not, however, a trade-off between so-called bad projects and good projects (kindergarten versus beach front hotel). A diverse portfolio allows for both risky and less risky investments, giving the private sector high financial returns while also addressing wider city/social needs. Private sector participation in urban investment is likely to increase if the portfolio offers a wide (diverse) range of urban assets in which to invest, including energy efficiency, urban development and urban regeneration. By combining different types of projects and fostering synergy between investments, a diversified portfolio with good financial returns on some projects would compensate for (cross-subsidise) the poor financial returns of other projects, which nevertheless achieve good non-financial impacts. Private sector participation, it can be argued, is likely to increase if the investment portfolio ranges across sectors and objectives to include integrated sustainable urban investments, and is also attractive to pension funds, commercial banks and regional development institutions. For instance, a cross-subsidy process between projects would allow schools to be built, importantly, without the need for grants or state aid; these investments give low financial returns but they also produce high non-financial impacts for a city.

However, the discussion above raises a critical point with regard to decision makers and how they choose to finance urban projects: programme administrators and other professionals who shape our cities are often educated and trained according to theories and experience they have derived largely through specialisation - so their problemsolving approach may in practice be carried out through a single disciplinary lens. These professionals are certainly aware of the impacts of other disciplines, and are likely to allow for such influences as they impact on, for example, funding for urban projects. Nevertheless, the tendency for decision makers to retreat into disciplinary silos and be predisposed to a specialised vantage point, although appropriate in certain contexts, is not helpful in the implementation of solutions to complex challenges posed by cities.

To make successful investment decisions it is therefore necessary to strike a balance between the interdependency between projects and the requirements for reaching an investment 'critical mass', i.e., have low investment risk and be attractive to the private sector. Given that the ultimate goal is to achieve benefits and to share risks and costs, cooperation between the public and private sector is crucial to the development of a well-designed framework for investment that will yield income for both participants: in the case of local institutions (to defray current expenditures) and for private partners (to remunerate their capital contributions).

By factoring cooperation into our definition of a portfolio approach for urban investment, as a prerequisite, we have also needed to re-envision city financial models by linking together some of the inevitable silos that arise through various urban initiatives (e.g., waste, energy, health, education, transport). Moreover, it has also been crucial to maximise the benefits of effective management of urban capital assets (e.g., human capital, natural capital and fixed capital). In order for cities to be globally competitive, investment via innovative financial and business models must be unlocked, and for this reason the proposed portfolio approach exceeds the simple analysis of returns of individual investment schemes, and capitalises on effective and integrated management of projects/investments in a focused response.

The development of the portfolio for urban investments intends to give stakeholders and decision makers a practical tool to structure and combine different typologies of projects. We can summarise the main reasons for implementing this approach, which are to:

- Combine different types of projects, thereby fostering synergy between investments to obtain a diversified portfolio where the good financial returns of some projects can compensate for (cross-subsidise) the 'poor' financial returns of other projects, which nevertheless achieve good non-financial impacts (socio-economic and environmental benefits).

- Increase private sector participation by structuring a portfolio offering feasible and attractive opportunities for investment in different types of urban assets, including energy efficiency, urban development and urban regeneration.

To effectively and efficiently structure the portfolio of projects, it is necessary to account for the evaluation of risks, since a lower level of risk exposure will be an attractive feature of the portfolio, particularly for the private sector. We have observed that urban projects are often susceptible to high levels of political/government risk, particularly around land purchase, planning and building permits, which can lead to protracted delays. In the evaluation of the portfolio both political and governmental risk are directly captured.

We have mentioned the administrative and political agencies which are the overseers of projects; these agents are 
fundamental to the effective implementation, successful completion and transparent monitoring and assessment of urban investments. So-called virtuous administrations may be small/middle size administrations and may not receive the largest capital share for projects, and it is noteworthy that virtuous administrations are sometimes overlooked by lending agencies and private investors who think large and thus focus mainly on the number and size of projects.

Against this background, we account in the evaluation of the portfolio for good governance by assessing political and government risk in project implementation, and thus we incorporate an independent measure of the level of quality of governance in cities where projects are carried out.

The graph below depicts an example of the portfolio approach for urban investments. Non-Financial Impacts are measured on the vertical axis "El", and Financial Impacts are shown as "Fl" on the horizontal axis. All yellow dots indicate single projects (6 in total), and the other dots (blue, red and pink) indicate various portfolio combinations of the projects (52 combined portfolios of the 6 projects).

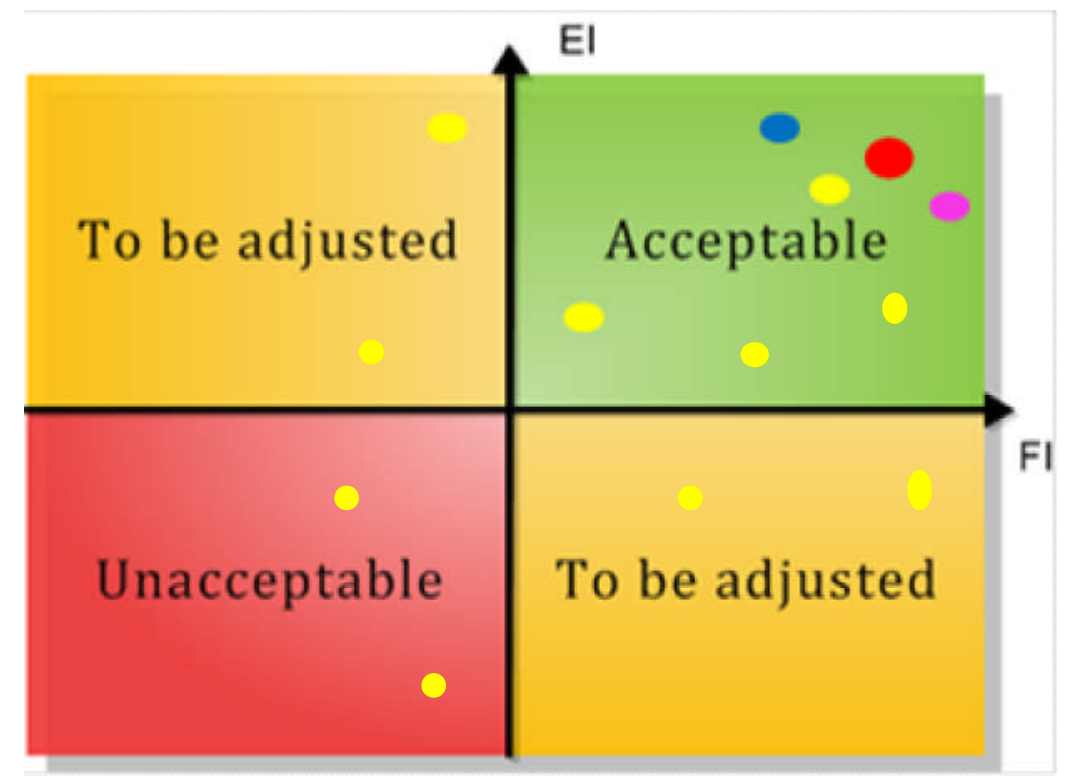

Figure 1: Portfolio Structuring: yellow dots are the projects; red, blue and magenta dots are the portfolios

The portfolio that our city should select is represented by the red dot. The visualisation of projects and their portfolio combinations is an important feature of the portfolio approach. In fact, the user of the portfolio software platform can easily evaluate different portfolio options (blue, pink and red dots). For instance, the user can choose the blue or the pink portfolio in accordance with a preference for either Non-Financial or Financial impacts. If the user values financial performance above non-financial impacts then the portfolio with the highest financial impact (pink dot on the graph) will be selected. Moreover, if new projects are added to the portfolio over time, the user can verify whether or not they improve overall performance of the portfolio.

The portfolio investment approach shows that it is possible to develop a practical decision-support system to assist stakeholders in assessing the performance of individual projects, and it also demonstrates how to combine projects into an integrated portfolio approach. This type of innovative financial tool for city investments can spur further financial innovations and facilitate connections and new ownership among citizens. As has always been the case, investors (private and public) will continuously find new ways to design, interlink, make sense of, and make decisions (albeit more quickly), based on for instance, public data on consumer behaviour. We are targeting the smartness of citizens rather than installed 'smart systems' hovering above cities. The platform of the portfolio we propose points up cities as dynamos of diversity which are reconfigured due to the creative capacity of their citizens. As a French general was said to have responded to his head gardener when told that his plans for creating an oak forest would take hundreds of years, "Quick then, we have not a moment to lose." 